\title{
Determination of orientation of horizontal stress and localized rotations of the orientation around faults and fractures from breakouts in a scientific drilling borehole
}

\author{
Weiren LIN ${ }^{1}$, En-Chao YEH $^{2}$ and Jih-Hao $\mathrm{HUNG}^{3}$ \\ ${ }^{1}$ Japan Agency for Marine-Earth Science and Technology (JAMSTEC), Japan \\ ${ }^{2}$ National Taiwan University, Taiwan. \\ ${ }^{3}$ National Central University, Taiwan
}

\begin{abstract}
To understand stress perturbations associated with minor faults and fractures, relationships between the faults, fractures, lithologic boundaries and stress changes in hole B of Taiwan Chelungpu-fault Drilling Project (TCDP) were investigated. Here, we reported four patterns of stress changes in the vicinity of faults, fractures and lithologic boundaries found in TCDP hole B: (i) the stress orientation (breakout azimuth) rotates abruptly (discontinuously) in the vicinity of the faults or fractures; (ii) the orientation rotates gradually; (iii) breakouts are suppressed at faults, fractures, or lithologic boundaries; and (iv) the orientation does not change across faults or fractures.
\end{abstract}

\section{INTRODUCTION}

Stress and earthquakes are interrelated: stress triggers earthquakes and earthquakes alter the shear and normal stresses on surrounding faults. Various stress measurements were carried out in a scientific drilling borehole, hole-B of Taiwan Chelungpu-fault Drilling Project (TCDP) penetrating the northern segment of the Chelungpu fault, drilled about 5 years after the 1999 Chi-Chi, Taiwan, earthquake. In the expected depth range of the Chelungpu fault, three major fault zones were encountered (e.g., Hirono et al., 2006). Lin et al. (2007a) had found an important fact that clearly recognizable principal stress rotations in the vicinity of the shallowest major fault zone, at 1133 $\mathrm{m}$ depth in hole $\mathrm{B}$, suggest that this fault zone ruptured during the 1999 earthquake. In order to reveal the details on stress perturbations associated with faults and fractures, Lin et al. (2009) investigated all the faults and large fractures from both FMI images of borehole and descriptions of drilling core samples in TCDP hole B, and measured the variations of principal horizontal stress orientation in the vicinity of the faults and fractures from borehole breakouts and drilling induced tensile fractures. They found four types of the relations between the faults/fractures and the breakouts and/or the tensile fractures which indicates the principal horizontal stress orientation in the TCDP hole-B, i) the stress orientation (breakout location) rotates abruptly (discontinuously) across the fault or fracture; ii) the orientation rotates gradually, iii) the breakout occurrence is suppressed at fractures or at boundary of lithology; iv) and the orientation does not change across fractures or faults. We summarize these four patterns of orientation changes of principal horizontal stresses around faults and fractures in this paper.

\section{TAIWAN CHELUNGPU-FAULT DRILLING PROJECT (TCDP)}

The large, destructive Chi-Chi earthquake (Mw 7.6) occurred in west-central Taiwan on 21 September 1999 as a result of convergence between the Philippine Sea and Eurasian plates (Ji et al., 2003). To understand the physics of the earthquake and the mechanism of rupture propagation, the TCDP drilled two vertical holes $40 \mathrm{~m}$ apart (hole A to an approximate depth of $2000 \mathrm{~m}$ and hole B to an approximate depth of $1350 \mathrm{~m}$ ) about $2 \mathrm{~km}$ east of the surface rupture (Figure 1), near the town of Da-Keng (Ma et al., 2006). The Chelungpu fault dips gently to the east $\left(30^{\circ}\right)$, and slips principally within and parallel to the bedding of the Pliocene Chinshui Shale (Figure 1b). The TCDP holes penetrate three major fault zones (e.g., Hirono et al., 2006) within the Chinshui Shale, which, despite its formal lithostratigraphic name, in this area is composed mainly of siltstone. Each of the three fault zones has components of wall rock, damage zone and fault core. By regional stratigraphic 


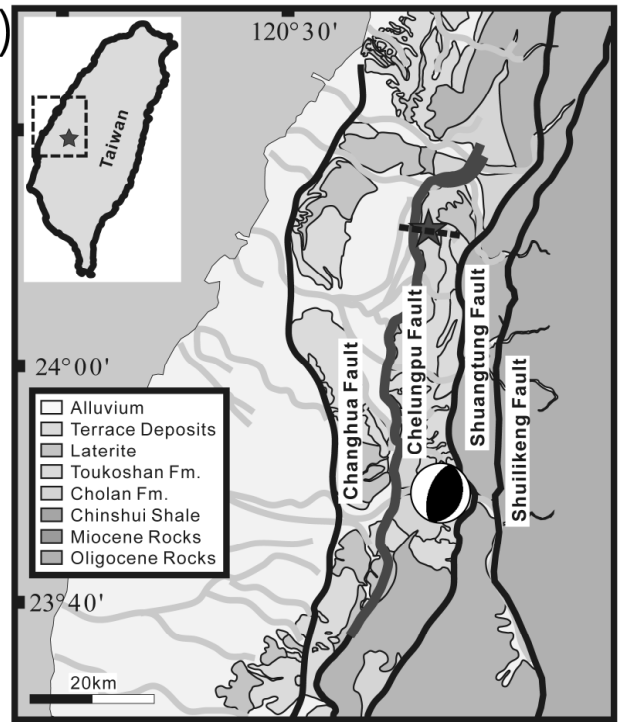

(b)

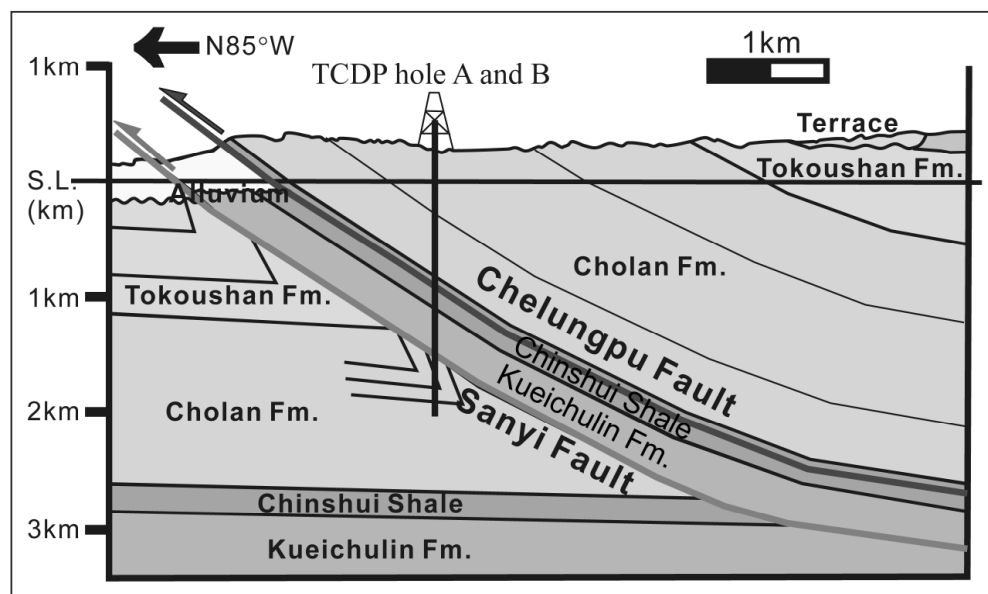

Figure 1. Schematic diagram illustrating the regional structures and geological section. (a) Geological map showing the formation distribution and the several faults in the central portion of the western Taiwan. The Chelungpu fault (thicker line) ruptured during the 1999 earthquake (after Yeh et al., 2007). The TCDP site is indicated by a star. The focal mechanism of the Chi-Chi main shock is located at the hypocenter of the Chi-Chi earthquake (Kao and Chen 2000). (b) Cross section through the drill site illustrates the relation between formations and major fault zones (after Yeh et al., 2007). The dashed line in (a) shows orientation and location of the section map (b).

constraint, however, we believe they will merge into one below certain depth since we did not find distinct stratigraphic offset on the surface geology.

A main objective of the TCDP was to determine the spatial distribution of the in situ stress and, in particular, to determine the stress state on and around the fault plane before, during, and after the earthquake. Previous stress-related studies in the area have reported the focal mechanisms of earthquakes occurring before the 1999 Chi-Chi earthquake (Yeh et al., 1991), and a stress tensor inversion of the Chi-Chi earthquake sequence (Kao and Angelier, 2001; Wang and Chen, 2001) revealed some regional stress information in the Taiwan area. Moreover, as part of the TCDP, Hung et al. (2009) determined stress magnitudes by hydraulic fracturing at four depths in hole B; Wu et al. (2007) and Lin W. et al. (2007a) obtained stress orientations mainly from borehole breakouts in hole A and hole B, respectively; Lin et al. (2007b) published preliminary results of three-dimensional stress determination by anelastic strain recovery (ASR) of core samples from hole A; and Yabe et al. (2008) measured stresses by acoustic emission (AE) and deformation rate analysis (DRA) of core samples. In addition, Haimson et al. (2009) have estimated the maximum principal horizontal stress magnitude by using the combination of borehole breakout width and rock strength data from true triaxial compression tests, which are considered able to replicate in situ stress conditions reliably.

\section{AN EXAMPLE OF STRESS ORIENTATION ROTATION}

Immediately below a minor fault (approximately $3 \mathrm{~cm}$ thick; logging depth, $975.4 \mathrm{~m} ; 30 / 130$ approximately) (Figure 2a-c), breakouts were identified that gradually rotate below the fault by $90^{\circ}$ approximately over an interval of approximately $2.6 \mathrm{~m}$, until reaching another fracture at $978.0 \mathrm{~m}$ depth (Figure 3). Below this fracture $(978.0 \mathrm{~m})$, the breakouts do not rotate but maintain an almost constant azimuth consistent with the regional stress orientation. Because the gradual stress rotation is local and the lithologies in hanging and foot walls are almost same (Figure 2a and $2 b$ ), the rotation might be interpreted due to presences of the minor fault.

Breakouts were absent in the hanging wall of the minor fault at $975.4 \mathrm{~m}$ logging depth described in above, but breakouts were present in the foot wall of the fault (Figure 2c). This shows that breakouts were suppressed at this minor fault. It is clear from the optical core images that the lithology of the hanging and foot walls is almost the same (Figure $2 \mathrm{a}$ and $2 \mathrm{~b}$ ), suggesting that their compressive strengths are likely to be approximately equal. Thus, we can infer that the stress state, especially the magnitude of the maximum principal horizontal 
(a)

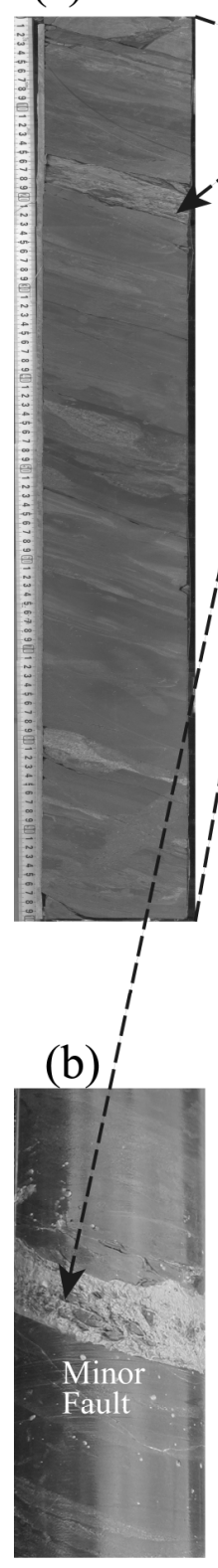

(c)

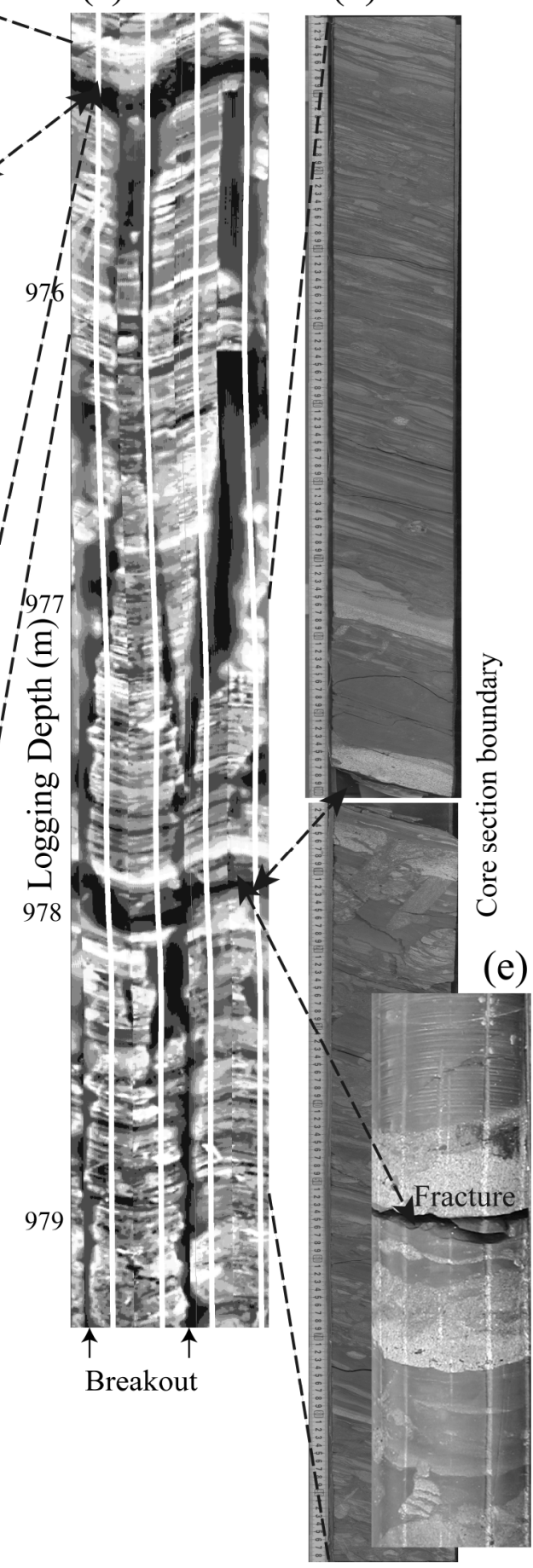

Figure 2. Examples of a gradual change in the stress orientation below a minor fault $(975.4 \mathrm{~m})$, of breakout suppression at the same minor fault and of no change in the stress orientation across a fracture $(978.0 \mathrm{~m})$. (a and d) Optical photographs of the flat surface of the half-core splits. (b and e) Optical images of the cylindrical core. (c) FMI electrical image.

stress, differs greatly between the two parts.

Stress orientations do not always change around faults and fractures. For example, around a fracture at $978.0 \mathrm{~m}$ depth (30/120 approximately), no stress

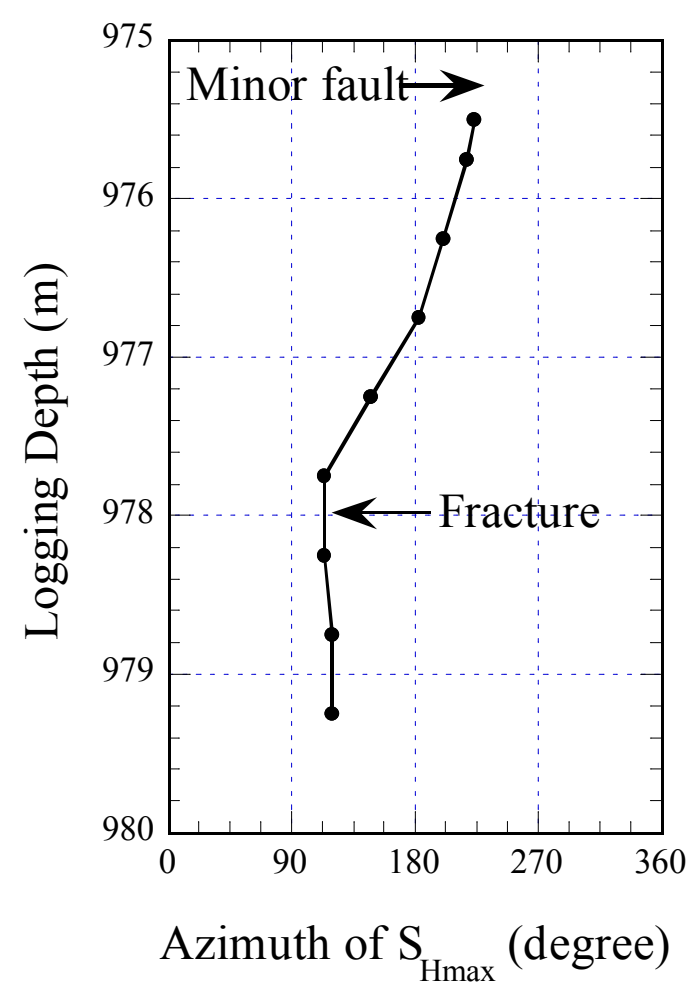

Figure 3. A plot of the $S_{H \max }$ azimuth over the corresponding depth interval showed in Figure 4.

orientation change was recognized (Figure $2 \mathrm{~d}, 2 \mathrm{e}$, and Figure 3). The lack of a stress orientation change suggests that the stress state remains mostly continuous around faults and fractures if the lithologies of the hanging and foot walls are similar and if shear stresses on the faults or fractures are less than their frictional strengths.

\section{CONCLUSIONS}

To understand stress perturbations associated with minor faults and fractures, relationships between the faults, fractures, lithologic boundaries and stress changes in TCDP hole B were investigated. Here, we reported four patterns of stress changes in the vicinity of faults and fractures found in TCDP hole B: (i) the stress orientation (breakout azimuth) rotates abruptly (discontinuously) in the vicinity of the faults or fractures; (ii) the orientation rotates gradually; (iii) breakouts are suppressed at faults, fractures, or lithologic boundaries; and (iv) the orientation does not change across faults or fractures. We recognized stress fluctuations, that is, heterogeneous mesoscale $(>10 \mathrm{~cm})$ stress distributions with regard to both stress orientation and magnitude. We also found that stress state changes were common in the vicinity of faults, fractures, and lithologic 
boundaries.

ACKNOWLEDGMENT: We gratefully acknowledge T. Hirono (Osaka Univ.), W. Soh, (JAMSTEC) and B. Haimson (Univ. of Wisconsin, USA) for their useful discussions, C.-Y. Wang, K.-F. Ma, S.-R. Song and Y.-B. Tsai (the principal investigators of TCDP, Taiwan), and Y. Kawamura, Y. Sanada, and T. Moe (JAMSTEC) for helpful support during the FMI logging in TCDP hole B. W. Lin thanks the Japan Society for the Promotion of Science (JSPS) for financial support (Grant-in-Aid for Scientific Research C: 19540453).

\section{REFERENCES}

Haimson, B., Lin, W., Oku, H., Hung, J.-H. and Song, S.-R., 2009. Integrating borehole breakout dimensions, strength criterion, and hydraulic fracturing to constrain the state of stress across the Chelungpu Fault, Taiwan, Tectonophysics, in-press. doi: 10.1016/j.tecto.2009.05.016.

Hirono, T. et al, 2006. High magnetic susceptibility of fault gouge within Taiwan Chelungpu fault: Nondestructive continuous measurements of physical and chemical properties in fault rocks recovered from hole B, TCDP, Geophys. Res. Lett., 33, L15303, doi:10.1029/2006GL026133.

Hung, J.-H., Ma, K.-F., Wu, Y.-H., Wu, H.-Y., Ito, H., Lin, W. and Yeh, E.-C., 2009. Structure geology, physical property, fault zone characteristics and stress state in scientific drill holes of Taiwan Chelungpu Fault Drilling Project, Tectonophysics, 466, 307-321.

Ji, C., Helmberger, D.V., Wald, D.J. and Ma, K.-F., 2003. Slip history and dynamic implications of the 1999 Chi-Chi, Taiwan, earthquake, J. Geophys. Res., 108, doi:10.1029/2002JB001764.

Kao, H. and Angelier, J., 2001. Stress tensor inversion for the Chi-Chi earthquake sequence and its implications on regional collision, Bull. Seismol. Soc. Am., 91, 1028-1040.

Kao, H., and Chen, W.-P., 2000. The Chi-Chi earthquake sequence: Active out-of-sequence thrust faulting in Taiwan. Science, 288, 2346-2349.

Lin, W., Yeh, E.-C., Ito, H., Hung, J.-H., Hirono, T., Soh, W., Ma, K.-F., Kinoshita, M., Wang, C.-Y. and Song, S.-R., 2007a. Current stress state and principal stress rotations in the vicinity of the Chelungpu fault induced by the 1999 Chi-Chi, Taiwan, earthquake, Geophys. Res. Lett., 34, L16307, doi:10.1029/2007GL030515.
Lin, W., Yeh, E.-C., Ito, H., Hirono, T., Soh, W., Wang, C.-Y., Ma, K.-F., Hung, J.-H. and Song, S.-R., 2007 b. Preliminary results of stress measurement by using drill cores of TCDP Hole-A: an application of anelastic strain recovery method to three-dimensional in-situ stress determination, Terr. Atmos. Ocean. Sci., 18, doi: 10.3319/TAO.2007.18.2.379(TCDP).

Lin, W., Yeh, E-C, Hung, J-H, Haimson, B., Hirono, T., 2009: Localized rotation of principal stress around faults and fractures determined from borehole breakouts in hole B of the Taiwan Chelungpu-fault Drilling Project (TCDP), Tectonophysics, in-press. doi: $10.1016 /$ j.tecto.2009.06.020

Ma, K.-F., Tanaka, H., Song, S.-R., Wang, C.-Y., Hung, J.-H., Tsai, Y.-B., Mori, J., Song, Y.-F., Yeh, E.-C., Soh, W., Sone, H., Kuo, L.-W. and Wu, H.-Y., 2006. Slip zone and energetics of a large earthquake from the Taiwan Chelungpu-fault Drilling Project, Nature, 444, 473-476, doi:10.1038/nature05253.

Wang, W.-H. and Chen, C.-H., 2001. Static stress transferred by the 1999 Chi-Chi, Taiwan, earthquake: Effects on the stability of the surrounding fault systems and aftershock triggering with a 3D fault-slip model, Bull. Seismol. Soc. Am., 91, 1041-1052.

Wu, H.-Y., Ma, K.-F., Zoback, M., Boness, N., Ito, H., Hung, J.-H. and Hickman, S., 2007. Stress orientations of Taiwan Chelungpu-Fault Drilling Project (TCDO) hole-A as observed from geophysical logs. Geophys. Res. Lett., 34, L01303, doi:10.1029/2006GL028050.

Yabe, Y., Song, S.-R. and Wang, C.-Y., 2008. In-situ stress at the northern portion of the Chelungpu fault, Taiwan, estimated on boring cores recovered from a 2-km-deep hole of TCDP, Earth Planets and Space, 60, 809-819.

Yeh,Y.-H., Barrier, E., Lin, C.-H. and Angelier, J., 1991. Stress tensor analysis in the Taiwan area from focal mechanisms of earthquakes, Tectonophysics, 200, 267-280.

Yeh, E.-C., Sone, H., Nakaya, T., Ian, K.-H., Song, S.-R., Hung, J.-H., Lin, W., Hirono, T., Wang, C.-Y., Ma, K.F., Soh, W. and Kinoshita, M., 2007. Core description and characteristics of fault zones from Hole-A of the Taiwan Chelungpu-fault Drilling Project. Terr. Atmos. Ocean. Sci., 18, 327-357, doi: 10.3319/TAO.2007.18.2.327(TCDP). 